\title{
Molecular docking analysis of novel Non- Nucleoside Reverse Transcriptase Inhibitors in development: implication for rational drug design
}

\author{
Udaya Pratap Singh ${ }^{1 *}$, Ramendra K Singh ${ }^{2}$ \\ From Frontiers of Retrovirology 2011 \\ Amsterdam, The Netherlands. 3-5 October 2011
}

\begin{abstract}
Background
Human immunodeficiency virus (HIV) from a family of retroviruses is a causative organism for acquired immuno deficiency syndrome (AIDS), affecting more than 40 million people worldwide [1]. Reverse transcription of the HIV single-stranded RNA genome into double-stranded DNA is one of the essential key step in the virus replication life-cycle and acts as lucrative target for drug action. Till date, out of 20 anti-HIV drugs approved for the treatment of HIV infection, eleven approved anti-HIV drugs target RT, and encompass three classes of agents that inhibit RT by different mechanisms (Nucleoside Reverse Transcriptase Inhibitors, NRTIs; Non-Nucleoside Reverse Transcriptase Inhibitors, NNRTIs; Nucleotide Reverse Transcriptase Inhibitors, NtRTIs) [2]. The NNRTIs serve as an increasingly important role in the therapy of HIV infection, due to their unique antiviral potency, high specificity and low toxicity. Present work illustrates the probable binding affinity, interatomic contacts and orientation of novel of NNRTIs in development at the allosteric site of the HIV-RT through an iterative computational process and molecular docking to explicate the necessary structural requirement for rational drug design.
\end{abstract}

\section{Material and methods}

Six NNRTIs in development were selected for the study viz. Etravirine, Rilpivirine, Calanolide A, IDX899, RDEA806 and Lersivirine). These selected molecules

\footnotetext{
* Correspondence: udaysingh98@gmail.com

'Department of Pharmaceutical Sciences, Sam Higginbottom Institute of Agriculture Technology \& Sciences, (Formerly Allahabad Agricultural Institute) Deemed-to-be-University, Allahabad, India

Full list of author information is available at the end of the article
}

were rigorously analyzed through Lipinski's Rule of 5 (Ro5) by molinspiration software [3]. In an order to explicate the binding affinity, interatomic contacts and orientation of NNRTIs at the active of HIV-RT, a molecular docking study were carried out by utilizing scoring function such as PLP1, PLP2, Jain, PMF, Lig_Internal_Energy, binding energy, and ultimately dock score. Docking study was performed by using the LigandFit as docking module within package of Discovery Studio 2.5. Position optimization of both ligand and proteins were performed by using all-atom CHARMm forcefield with Adopted Basis set Newton Raphson minimization algorithm until the root mean square (r.m.s) gradient for potential energy was less than $0.05 \mathrm{kcal} / \mathrm{mol} / \AA$. The cavity within a receptor defined as active site and an input site sphere was defined over the active site with a radius of $5 \AA$.

\section{Results}

All six molecules successfully passed the Lipinski's Ro5 filter to be as a probable drug candidate except some minor violations. In terms of molecular docking, they presented excellent scoring and binding affinity towards the receptor due to the close interatomic contacts through strong H-bonds Lys103 (Calanolide A), His235, Tyr318 (RDEA806), Lys101 (Rilpivirine, Etravirine) Val179 (Etravirine), pi-pi Tyr181 (IDX899, RDEA806, Rilpivirine, Lersivirine) and pi-cation interactions through Lys101 (RDEA806), Tyr103 (Rilpivirine).

\section{Conclusion}

As a concluding remark, preliminary screening by Lipinski's Ro5 acted as filter to obtain potential molecule from large datasets, whereas, pi-pi interaction was coined as a major interatomic interaction for stabilizing 
receptor-ligand complex and minor with hydrogen bonding and pi-cation interaction. We have anticipated a pivotal facet for designing the next generation of NNRTIs with improved activity based upon molecular docking studies.

\section{Acknowledgement}

Financial assistance from Department of Biotechnology (DBT) and Indian Council of Medical Research (ICMR), Government of India is sincerely

acknowledged.

\section{Author details}

'Department of Pharmaceutical Sciences, Sam Higginbottom Institute of Agriculture Technology \& Sciences, (Formerly Allahabad Agricultural Institute) Deemed-to-be-University, Allahabad, India. ${ }^{2}$ Nucleic Acids Research

Laboratory, Department of Chemistry, University of Allahabad, Allahabad,

India.

Published: 3 October 2011

\section{References}

1. World Health Organisation: .[http://www.who.int/tb/hiv/faq/en/], Accessed on 22/08/11.

2. Pawels R: New non-nucleoside reverse transcriptase inhibitors (NNRTIs) in development for the treatment of HIV infections. Curr Opin Pharmacol 2004, 4:437-446.

3. Molinspiration: [http://www.molinspiration.com/cgi-bin/properties].

doi:10.1186/1742-4690-8-S2-P82

Cite this article as: Singh and Singh: Molecular docking analysis of novel Non-Nucleoside Reverse Transcriptase Inhibitors in development: implication for rational drug design. Retrovirology 2011 8(Suppl 2):P82.

\section{Submit your next manuscript to BioMed Central} and take full advantage of:

- Convenient online submission

- Thorough peer review

- No space constraints or color figure charges

- Immediate publication on acceptance

- Inclusion in PubMed, CAS, Scopus and Google Scholar

- Research which is freely available for redistribution

Submit your manuscript at www.biomedcentral.com/submit
Ciomed Central 